Journal of Telenursing (JOTING)

Volume 3, Nomor 1, Juni 2021

e-ISSN: 2684-8988

p-ISSN: 2684-8996

DOI: https://doi.org/10.31539/joting.v3i1.2031

\title{
PENDIDIKAN BERKELANJUTAN MELALUI E-LEARNING BAGI PERAWAT SUATU PROGRAM INOVASI
}

\author{
Rita Setianingrum ${ }^{1}$, Rr. Tutik Sri Hariyati ${ }^{2}$, Desnita Fitri ${ }^{3}$ \\ Universitas Indonesia ${ }^{1,2}$ \\ Rumah Sakit Pusat Angkatan Darat Gatot Soebroto ${ }^{3}$ \\ ritasetyaningrum9760@gmail.com ${ }^{1}$
}

\begin{abstract}
ABSTRAK
Penelitian ini bertujuan menganalisis dan mengembangkan metode pembelajaran untuk meningkatkan kompetensi perawat dalam pendidikan berkelanjutan melalui e-learning di ruang rawat inap. Metode yang digunakan adalah pilot project mulai dari pengumpulan data, analisis masalah, penetapan prioritas masalah, penyusunan plan of action, implementasi serta evaluasi. Hasil penelitian menunjukan bahwa setelah pembelajaran e-learning didapatkan data ada kenaikan ilmu pengetahuan perawat diruang rawat inap bedah dengan rata-rata kenaikan dari pretest sampai post test sebesar $29,59 \%$. Kepuasan pasien terhadap mutu asuhan keperawatan sebesar 55\% merasa puas, sementara $45 \%$ merasa tidak puas. Kepuasan perawat yang menyatakan bahwa perawat puas terhadap profesi keperawatan adalah 96\%, sedangkan tidak puas sebesar $4 \%$ dari total responden 28 perawat. Perawat yang menyatakan bahwa pelatihan berkelanjutan melalui e-learning dapat meningkatkan pengetahuan adalah sebanyak 12 perawat (setuju) dan 16 perawat (sangat setuju) dari 28 responden. Simpulan, metode pembelajaran pendidikan berkelanjutan melalui e-learning mampu meningkatkan kompetensi perawat di ruang rawat inap bedah.
\end{abstract}

Kata Kunci: CPD, E-Learning, Kepuasan, Perawat

\section{ABSTRACT}

This study aims to analyze and develop learning methods to improve nurses' competence in continuing education through e-learning in inpatient rooms. The method used is a pilot project starting from data collection, problem analysis, determination of problem priorities, preparation of a plan of action, implementation and evaluation. The results showed that after e-learning learning, it was found that there was an increase in the knowledge of nurses in the surgical inpatient room with an average increase of $29.59 \%$ from pretest to posttest. 55\% of patients' satisfaction with the quality of nursing care was satisfied, while $45 \%$ felt dissatisfied. The nurses' satisfaction who stated that the nurses were pleased with the nursing profession was $96 \%$, while $4 \%$ of the total respondents were not satisfied with the 28 nurses. There were 12 nurses (agreed) and 16 nurses (strongly approved) from 28 respondents who stated that continuous training through e-learning could increase knowledge. In conclusion, the continuing education learning method through e-learning can improve nurses' competence in surgical inpatient rooms.

Keywords: CPD, E-Learning, Satisfaction, Nurse 


\section{PENDAHULUAN}

Rumah sakit dalam memberikan pelayanan kesehatan perlu ditunjang dengan Sumber Daya Manusia (SDM) yang kompeten. Keperawatan sebagai bagian dari integral dari pelayanan kesehatan rumah sakit mempunyai peranan penting dalam kualitas pelayanan. Upaya pengembangan staf keperawatan sangat diperlukan dalam pengembangan karirnya. Pendidikan berkelanjutan berperan penting dalam meningkatkan kompetensi perawat sesuai dengan jenjang karir. Pengembangan jenjang karir bagi perawat mengembangkan sistem penghargaan yang efektif, meningkatkan ketrampilan dan pengembangan ilmu dengan adanya pengembangan ilmu pengetahuan, skill dan attitude dalam memberikan asuhan keperawatan pada pasien (Pertiwi \& Hariyati, 2019).

Pengembangan kompetensi perawat pelaksana, sangat dipengaruhi peran kepala ruangan untuk menunjang peningkatan mutu asuhan keperawatan serta mampu menginspirasi dan memotivasi serta dapat meningkatkan integritas organisasi khususnya dalam peningkatan kompetensi (Lehtonen et al., 2018). Kepala ruangan sebagai first line manager harus memiliki kompetensi yaitu keterampilan, pengetahuan dan kemampuan memandu praktik para pemimpin perawat. Pemimpin perawat yang sukses harus mampu menciptakan jiwa pemimpin dalam diri sendiri, pengembangan pribadi dan professional, akuntabilitas, perencanaan karir, disiplin dalam perjalanan pribadi serta mengoptimalkan jiwa pemimpin dalam diri.

Komisi Akreditasi Rumah Sakit (2018) menyatakan bahwa setiap staf berhak memperoleh pendidikan dan pelatihan berkelanjutan. Pendidikan dan pelatihan diatur dalam Standar Akreditasi Joint Commission International edisi 6 pada Bab Staf Qualification and Education (SQE) pasal 8 menyatakan bahwa tiap anggota staf diberikan pelatihan internal serta pendidikan dan pelatihan lain yang berkelanjutan untuk menyokong atau meningkatkan keterampilan dan pengetahuannya.

Pendidikan Keperawatan Berkelanjutan (PKB) adalah proses pengembangan keprofesian yang meliputi berbagai kegiatan yang dilakukan perawat dalam kapasitasnya sebagai praktisi, untuk mempertahankan dan meningkatkan profesionalismenya sebagai perawat sesuai standar kompetensi yang ditetapkan Hal ini menunjukkan korelasi positif antara Continuing Professional Development (CPD) dan kepuasan perawat, dimana semakin baik persepsi CPD akan meningkatkan kepuasan perawat, sedangkan korelasi negatif adalah ditemukan antara sistem implementasi dan kepuasan. Pendidikan professional yang relevan dengan bidang pekerjaannya memiliki potensi untuk meningkatkan kepuasan kerja dan retensi perawat klinis, sehingga pada akhirnya secara langsung dan positif mempengaruhi perawatan pasien. Pendidikan berkelanjutan terdiri dari pendidikan formal dan pendidikan nonformal, dalam rangka mempertahankan dan meningkatkan kompetensi perawat agar tetap dapat melaksanakan tugas berorientasi pada proses dan keselamatan klien, memutus rantai kebosanan dalam bekerja, meningkatkan motivasi dan menurunkan turnover (Sulistiyowati, 2020).

E-learning merupakan sistem pembelajaran tanpa menggunakan kertas dengan sistem pembelajaran yang cukup fleksibel. Selain itu, pembelajaran ini juga bermanfaat untuk berkomunikasi secara mudah melalui fasilitas internet secara regular atau kapan saja kegiatan berkomunikasi itu dilakukan tanpa dibatasi jarak, tempat dan waktu, pembelajar bisa belajar terstruktur melalui internet sehingga bisa menilai seberapa jauh bahan ajar yang dipelajari, mereview bahan ajar tersimpan di komputer, dapat diikuti dengan jumlah peserta yang banyak sehingga ilmu pengetahuan dan wawasan lebih luas. Pembelajar berubah dari pasif menjadi aktif, relatif sangat efisien, bisa dipakai 
orang, dapat belajar kapan saja, tanpa face to face, pembelajar dapat berada dimana saja, asalkan mereka memiliki akses internet untuk membuka, tidak perlu tempat/ruangan khusus buat pembelajaran e-learning, pembelajar dapat mengatur kecepatan mereka sendiri, sangat cocok untuk orang yang keterbatasan waktu dengan kesibukan lainnya, menurunkan biaya operasional seperti biaya listrik untuk tempat belajar dengan ruangan yang besar, biaya air yang digunakan oleh peserta dalam pelatihan, biaya kertas untuk fotokopi/printer materi yang akan disampaikan kepada peserta, biaya konsumsi, biaya pengajar. Sementara kekurangan dari e-learning antara lain kurangnya interaksi antara pemberi materi dengan yang menerima materi (Muhammad et al., 2020).

Elektronik learning (e-learning) merupakan bentuk pengembangan CPD berbasis $w e b$, efektif dalam meningkatkan kompetensi perawat, pendekatan yang efektif terhadap masalah praktik yang sering dihadapi perawat baru dalam melihat tanda-tanda keadaan kritis pasien (Driscoll, 2018). Menurut Setianingrum \& Rachmi (2019) e-Learning memberikan berbagai manfaat positif kepada perawat baru dalam menghadapi persiapan kerja dilahan praktik, selain itu memberikan dukungan psikologis karena dapat menurunkan tingkat kecemasan yang dihadapi oleh perawat baru. Pendekatan pembelajaran e-learning dibagi menjadi dua yaitu: 1) asynchronous, merupakan aktifitas yang menggunakan teknologi dalam bentuk blogs, wikis, email dan diskusi boards; 2) synchronous, merupakan aktifitas yang menggunakan teknologi informasi yang mengharuskan penerima materi menggunakan waktu yang bersamaan.

Rumah Sakit X memiliki 740 tempat tidur atau Bed Occupancy Rate (BOR) dengan rata-rata $85-90 \%$ di ruangan rawat inap, sementara ruangan rawat inap bedah memiliki 80 tempat tidur dengan jumlah perawat sebanyak 78 orang dan 3 kepala ruangan. BOR yang cukup tinggi tersebut memerlukan kekuatan SDM kesehatan dan administrasi yang handal untuk melaksanakan pelayanan yang bermutu. Kerja yang sangat overload membuat perawat lupa akan dirinya untuk mengembangkan diri dalam pendidikan berkelanjutan khususnya non formal seperti mengikuti kegiatan seminar atau training baik yang dilakukan di dalam rumah sakit maupun luar rumah sakit. Data yang diperoleh menunjukkan bahwa $18,3 \%$ perawat yang mengikuti pendidikan berkelanjutan dari seluruh total staf perawat yang berjumlah 1365 orang.

Berdasarkan uraian di atas, maka peneliti tertarik untuk mengkaji permasalahan yang terjadi menggunakan fishbone terkait pengembangan pendidikan berkelanjutan non formal melalui e-learning bagi perawat pelaksana di ruang rawat inap. Hal ini dirasa perlu karena e-learning merupakan salah satu metode pelatihan yang dapat diaplikasikan di saat pandemi COVID-19 seperti sekarang ini.

\section{METODE PENELITIAN}

Metode yang digunakan adalah pilot project mulai dari pengumpulan data, analisis masalah dengan pendekatan fishbone yang dikelompokan dalam 5 tools manajemen yaitu man, money, method, machine dan material serta ditambah environment, penetapan prioritas masalah, penyusunan plan of action, implementasi serta evaluasi uang rawat yang digunakan adalah instalasi rawat inap bedah. Pengumpulan data di dapatkan dengan cara wawancara, kuesioner, dan memanfaatkan data sekunder di rumah sakit. Pelaksanaan manajemen Planning, Organizing, Staffing, Actuating, Controlling (POSAC).

Tahap awal pengumpulan data melalui kuesioner diberikan kepada perawat pra pk yang ada diruang rawat inap bedah sejumlah 37 orang mengenai pembelajaran lewat $e$ learning. Tahap kedua wawancara dilakukan kepada ketiga orang kepala ruang 
sebanyak satu kali setiap partisipan selama 15-30 menit dengan menggunakan instrument panduan wawancara yang mengacu Planning, Organizing, Staffing, Actuating, Controlling (POSAC). Identifikasi data dilakukan selama dua minggu di ruang rawat inap bedah. Tahap ketiga uji coba pelaksanaan pembelajaran e-learning. Pilot project ini merupakan sebuah proyek inovasi yang sudah mendapatkan ijin dari Rumah Sakit X Nomor B/3H51x1 2020.

\section{HASIL PENELITIAN}

Berdasarkan hasil wawancara dengan ketiga kepala ruangan menyatakan bahwa saat pandemi COVID-19 ini terkait program pendidikan berkelanjutan tidak berjalan dengan optimal. Wawancara dari bidang keperawatan didapatkan hasil bahwa $100 \%$ kepala ruangan membuat perencanaan pengembangan staf. Hasil kuesioner terhadap perawat pelaksana terkait perencanaan seorang kepala ruangan menciptakan perubahan (agen perubahan) di ruangan di era 4.0 seperti pembelajaran lewat e-learning sebanyak $71 \%$ dan $29 \%$ perawat pelaksana dari total perawat 78 orang diruang bedah yang menyatakan tidak ada agen perubahan untuk saat ini. Gambaran di ruang rawat inap bedah dari hasil kuesioner memungkinkan untuk dikembangkan pendidikan berkelanjutan non formal sebanyak 66,6\% (52 dari 78 orang) serta belum optimalnya dilakukan bimbingan terkait pembelajaran lewat elektronik (e-learning), pemberian edukasi terkait digital. Hasil kuesioner perawat pelaksana rawat inap didapatkan data bahwa 100\% e-learning sangat bermanfaat saat pandemi COVID-19.

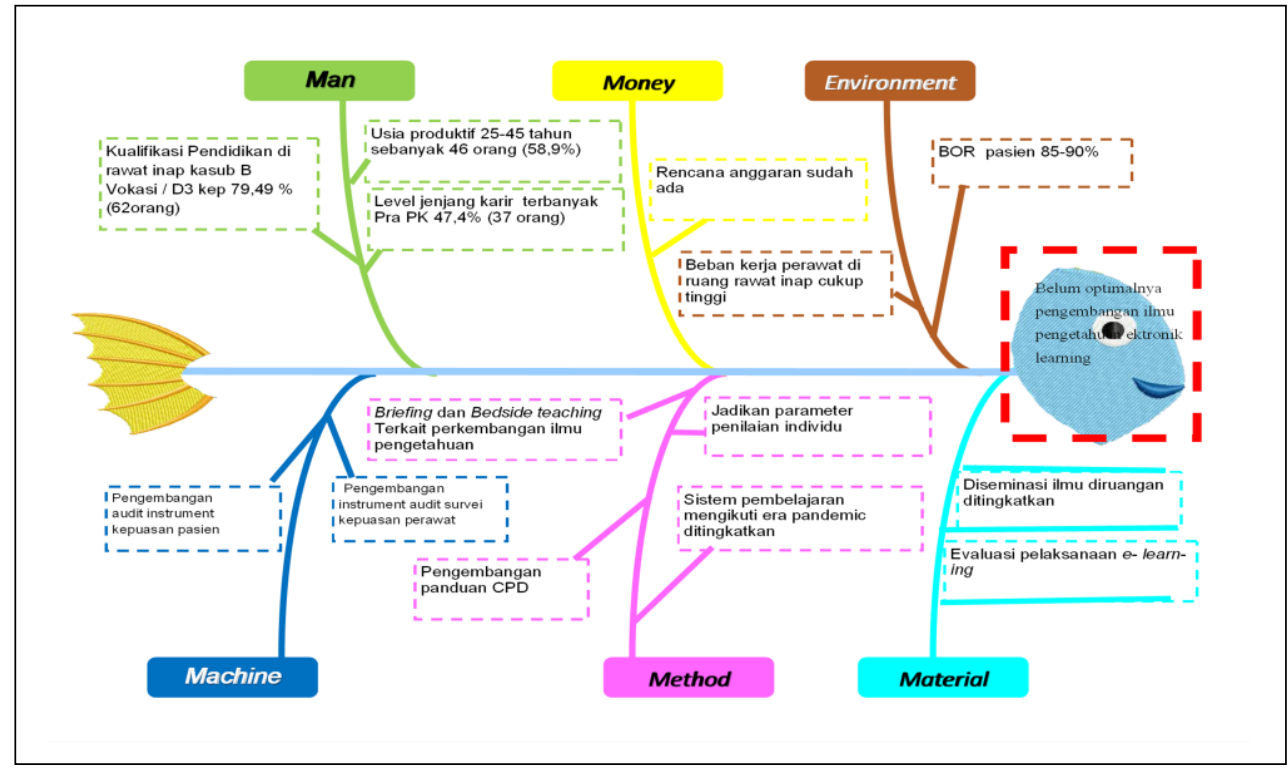

Gambar. 1

Analisis Masalah Pengembangan Pendidikan Berkelanjutan Lewat E-Learning dengan Diagram Fishbone

Pelaksanaan pendidikan non formal seperti webinar selama pandemi ini sudah mulai diikuti, tetapi belum mencapai $100 \%$ atau belum mencapai 20 jam. Hasil wawancara dengan infolahta didapatkan data bahwa sudah memiliki rencana strategis dan program kerja pengembangan piranti lunak dan piranti keras, sangat memungkinkan untuk bisa dilaksanakan pengembangan pembelajaran melalui elektronik. 
Pengaplikasian langsung pengembangan pendidikan berkelanjutan berbasis elektronik belum optimal. Peran Leader Role dan Liaison Role belum optimal khususnya pengembangan pendidikan berkelanjutan melalui e-learning, belum optimal dalam pendokumentasian monitoring dan melakukan audit pelaksanaan pendidikan berkelanjutan. Peran Informasional terkait pencapaian kinerja tim dan hambatan dalam pelaksanaan program Pendidikan berkelanjutan diruangan belum optimal, memotivasi dan menjadi spoken leader dalam menyampaikan aspirasi dan kendala staf saat mengikuti pendidikan berkelanjutan lewat e-learning. Peran Decisional Kepala Ruangan dalam pengambilan keputusan dengan mempertimbangan berbagai aspek dan didasari kebijakan atau regulasi rumah sakit terkait elektronik learning belum optimal karena terkait sumber daya manusia yang tidak memungkinkan.

Tabel. 1

Distribusi Presentase Perawat Pelaksana Rawat Inap Bedah tentang Materi Pembelajaran E-Learning

\begin{tabular}{ccccc}
\hline Materi Pembelajaran $E-$ & \multicolumn{2}{c}{ Pretest } & \multicolumn{2}{c}{ Posttest } \\
\cline { 2 - 5 } Learning & $\mathrm{N}$ & $\%$ & $\mathrm{~N}$ & $\%$ \\
\hline Askep Pasien COVID-19 & 20 & 76 & 20 & 90,77 \\
\hline Sasaran Keselamatan Pasien & 20 & 65 & 20 & 90 \\
\hline Pengembangan Kompetensi & 20 & 36 & 20 & 85 \\
\hline
\end{tabular}

Tabel 1 menunjukan bahwa terjadi kenaikan persentase setelah mengikuti pembelajaran. Askep pasien COVID-19 didapatkan pretest $76 \%$, post test $90,77 \%$, materi sasaran keselamatan pasien didapatkan hasil pretest $65 \%$, post test $90 \%$, materi pengembangan kompetensi pretest $36 \%$, post test $85 \%$.

Tabel. 2

Presentase Kepuasan Pasien terhadap Mutu Asuhan Keperawatan di Rawat Inap Bedah

\begin{tabular}{ccc}
\hline Kepuasan terhadap Mutu Asuhan & Pretest & Posttest \\
\cline { 2 - 3 } Keperawatan & $\mathrm{N}$ & $\%$ \\
\hline Puas & 20 & 55 \\
\hline Tidak Puas & 20 & 45 \\
\hline
\end{tabular}

Data tabel 2 menunjukkan bahwa kepuasan pasien yang menyatakan bahwa pasien yang dirawat inap bedah menyatakan puas terhadap mutu asuhan keperawatan sejumlah 55\%, sementara tidak puas sejumlah 45\% dari total responden 20 pasien.

Tabel. 3

Presentase Kepuasan Perawat terhadap Profesi Keperawatan di Rawat Inap Bedah

\begin{tabular}{ccc}
\hline Kepuasan terhadap Profesi & Pretest & Posttest \\
\cline { 2 - 3 } Keperawatan & $\mathrm{N}$ & $\%$ \\
\hline Puas & 28 & 96 \\
\hline Tidak Puas & 28 & 4 \\
\hline
\end{tabular}

Data tabel 3 di atas menunjukan bahwa kepuasan perawat yang menyatakan bahwa perawat puas terhadap profesi keperawatan adalah $96 \%$ sedangkan tidak puas sebesar $4 \%$ dari total responden 28 perawat. 
Tabel. 4

Jumlah Perawat Pelaksana di Rawat Inap Bedah yang Menyatakan Pelatihan Melalui E-Learning Membantu Meningkatkan Pengetahuan

\begin{tabular}{ccc}
\hline Kepuasan Perawat terhadap Profesi & Pretest & Posttest \\
\cline { 2 - 3 } Keperawatan & $\mathrm{N}$ & $\%$ \\
\hline Setuju & 28 & 42,9 \\
\hline Tidak Setuju & 28 & 0 \\
\hline Sangat Setuju & 28 & 57,1 \\
\hline
\end{tabular}

Data tabel 4 menunjukan bahwa pernyataan perawat yang menyatakan pelatihan berkelanjutan melalui e-learning membantu meningkatkan pengetahuan sebesar 12 perawat atau $42,9 \%$ (setuju), 0 perawat (tidak setuju), 16 perawat atau 57,1\% (sangat setuju) dari total 28 responden.

\section{PEMBAHASAN}

Data hasil analisis mengenai pembelajaran E-learning berdasarkan pretest dan post test. Menunjukan bahwa Terjadi kenaikan persentase setelah mengikuti pembelajaran. Askep pasien COVID-19 didapatkan pretest $76 \%$, post test $90,77 \%$, materi sasaran keselamatan pasien didapatkan hasil pretest $65 \%$, post test $90 \%$, materi pengembangan kompetensi pretest $36 \%$, post test $85 \%$. Penelitian ini sejalan Pandemi COVID-19 yang melanda dunia termasuk salah satunya Indonesia membutuhkan perhatian khusus di berbagai tenaga kesehatan, salah satunya keperawatan. Permasalahan yang dihadapi perawat dalam penanganan COVID-19 adalah faktor kepadatan pasien. Beban kerja yang cukup tinggi ini, membuat para manajer keperawatan memikirkan kebutuhan tenaga yang terampil dan kompeten serta attitude dengan klasifikasi tertentu untuk menangani pasien COVID-19, untuk itu dibutuhkan percepatan pendidikan berkelanjutan melalui e-learning (Zhang et al., 2020).

Elektronik learning (e-learning) merupakan bentuk pengembangan CPD berbasis $w e b$, efektif dalam meningkatkan kompetensi perawat, pendekatan yang efektif terhadap masalah praktik yang sering dihadapi perawat baru dalam melihat tanda-tanda keadaan kritis pasien (Driscoll, 2018). E-learning sebagai metode orientasi perawat baru menunjukkan evaluasi yang baik. Penggunaan E-learning dapat meningkatkan motivasi pengguna dan tingkat keyakinan pemakainya (Lisum \& Sianturi, 2020). Pembelajaran dengan simulasi menggunakan e-learning merupakan pendekatan yang efektif terhadap masalah praktik yang sering dihadapi perawat baru di era pandemi COVID-19 (Driscoll, 2018).

Karakteristik e-learning antara lain memanfaatkan teknologi elektronik sehingga informasi mudah dan cepat, memanfaatkan media komputer seperti jaringan komputer atau media digital, menggunakan materi dengan sistem pembelajaran mandiri, materi pembelajaran disimpan komputer atau media lainnya yang mudah diakses, untuk mengetahui hasil kemajuan dalam proses belajar mengajar, dapat memberikan informasi kepada bagian administrasi (Inggriyani et al., 2019). Pembelajaran e-learning dapat meningkatkan keterampilan dan pengetahuan. Ketrampilan yang diperlukan untuk memengaruhi secara positif dan memotivasi adanya perubahan untuk menjadi sukses. Konsep umum yang digunakan untuk menjelaskan proses perubahan biasanya menggambarkan interaksi agen perubahan dengan lingkungan internal dan eksternal. Interaksi agen perubahan dalam layanan kesehatan sistem tergantung pada tiga hambatan: diri, target lingkungan, dan lingkungan eksternal. 
Pemimpin yang efektif mendukung setiap anggota tim untuk mengenali, merasa diberdayakan dan menghargai peran mereka. Ada berbagai pendekatan untuk kepemimpinan yang mungkin bermanfaat dalam pengaturan perawatan kesehatan, dan para pemimpin harus memperhatikan tantangan dan peluang yang ada untuk meningkatkan perawatan. Karakteristik penting dari seorang pemimpin yang efektif meliputi: memiliki hubungan yang penuh kasih dan nyata; terlibat dan memberdayakan; menjadi berani, mengenali talenta dan mengembangkan tim; menunjukkan kredibilitas, visibilitas, refleksi dan perawatan diri. Dengan mengembangkan karakteristik ini, perawat dapat bergerak ke arah gaya kepemimpinan yang semakin inovatif, menarik dan inklusif. Ini akan memungkinkan staf untuk memberikan perawatan penuh kasih, yang merupakan pusat bagi profesi keperawatan (Quinn, 2017).

Program pendidikan berkelanjutan melalui e-learning untuk perawat pelaksana cukup efektif dalam meningkatkan pengetahuan dan keterampilan serta mampu membuka wawasan yang lebih luas mengenai standar komptensi perawat pelaksana sesuai dengan jenjang karir. Adanya program e-learning yang dilaksanakan oleh seluruh keperawatan mampu mendobrak dunia keperawatan dalam era digital dalam pengembangan kompetensi untuk meningkatkan mutu asuhan dan pelayanan keperawatan. Peningkatan kompetensi perawat dalam memberikan pelayanan kesehatan tidak terlepas dengan adanya dukungan dari manajer keperawatan. Dunia keperawatan mampu mengikuti program pembelajaran e-learning yang dirasakan selama ini sangat berguna antara lain dapat belajar kapan saja dan dimana saja dengan akses internet yang cukup kuat, mampu mengatur kecepatan dengan sendiri dengan beragam bakat dan waktu yang terbatas, serta menurunkan biaya transportasi, biaya pengadaan (Damanik, 2020).

E-learning merupakan bentuk pengembangan CPD berbasis web, efektif dalam meningkatkan kompetensi perawat, pendekatan yang efektif terhadap masalah praktik yang sering dihadapi perawat baru dalam melihat tanda-tanda keadaan kritis pasien (Driscoll, 2018). E-learning untuk saat ini merupakan suatu kebutuhan dengan memanfaatkan teknologi komputer dalam kegiatan belajar mengajar. E-learning dapat meningkatkan kualitas pembelajaran dan materi ajar, kualitas aktifitas dan kemandirian peserta didik serta komunikasi antara pendidik dan peserta didik maupun antar peserta didik itu sendiri (Inggriyani et al., 2019). E-learning memberikan berbagai manfaat positif kepada perawat baru dalam menghadapi persiapan kerja dilahan praktik, selain itu memberikan dukungan psikologis karena dapat menurunkan tingkat kecemasan yang dihadapi oleh perawat baru (Setianingrum \& Rachmi, 2019).

Keberhasilan fungsi manajerial tidak terlepas dari faktor menjaga kualitas dan mutu pelayanan keperawatan, mutu profesi serta keselamatan. oleh karena itu dibutuhkan pengarahan dan controling oleh manajemen. Dukungan dan motivasi yang ditunjukkan pimpinan rumah sakit, komunikasi dan memotivasi untuk melakukan inovasi dan perbaikan sangat mendukung peningkatan kualitas manajemen keperawatan (Masiyati et al., 2020).

CPD sangat penting untuk mempertahankan dan memperbaharui pengetahuan dasar serta membantu praktisi dalam menggabungkan antara pengetahuan dan ketrampilan untuk meningkatkan praktek secara profesional yang berfokus Patient Center Care (PCC). CPD juga meningkatkan kepercayaan diri perawat, motivasi dan meningkatkan kesempatan jaringan serta peningkatan sumberdaya komitmen organisasi. Evaluasi CPD yang dilakukan oleh manajer keperawatan untuk memberikan kesempatan bagi pemimpin perawat meningkatkan pengetahuan dan kepercayaan serta 
meningkatkan kepuasan pasien yang lebih baik, menerapkan CPD dengan mentoring untuk memajukan keterampilan kepemimpinan (Oyenuga et al., 2020). Pendokumentasi kedalam logbook, portopolio perawat yang mengembangkan pendidikan dan pelatihan serta mengusulkan kepada bidang keperawatan mengenai clinical privillage.

Analisis manajemen strategis upaya peningkatan pembelajaran pendidikan berkelanjutan melalui e-learning dengan memilih strategi adaptif yang dilakukan dengan cara menambahkan input organisasi untuk kualitas sumber daya keperawatan melalui fungsi ketenagaan. Integrasi vertikal ke belakang (backward vertical integration) menambah bagian baru dalam alur distribusi untuk produk dan layanan saat ini. Organisasi berusaha memenuhi kebutuhan inputnya terhadap risiko resistance to change dalam penggunaan digital, sehingga memerlukan pemecahan masalah dengan metode perubahan Teori Kurt Lewin. Teori perubahan Lewin terdiri dari tiga tahap yaitu unfreezing, moving, and refreezing. Konsep ini dikenal sebagai paradigma klasik dalam mengelola perubahan organisasi yang enggan untuk melakukan perubahan (Mellita \& Elpanso, 2020).

\section{SIMPULAN}

Metode pembelajaran pendidikan berkelanjutan melalui e-learning mampu meningkatkan kompetensi perawat di ruang rawat inap bedah. Inovasi penggunaan $e$ learning dapat meningkatkan motivasi pengguna dan tingkat keyakinan pemakainya. Pembelajaran dengan simulasi menggunakan e-learning merupakan pendekatan yang efektif terhadap masalah praktik yang sering dihadapi perawat baru di era pandemi COVID-19.

\section{SARAN}

Diharapkan rumah sakit agar selalu mendukung penuh program pendidikan berkelanjutan bagi perawat dalam memberikan pelayanan kesehatan. Rumah sakit dalam menjaga mutu pelayanan harus ditunjang oleh kualitas SDM yang terampil dan kompeten sesuai dengan area kerja, untuk itu diharapkan agar prototype mengenai $e$ learning bisa dilanjutkan dan diterapkan. Program e-learning bisa berjalan dengan baik apabila ada SDM yang mengelola, untuk itu dibutuhkan suatu tata kelola yang baik dalam pelaksanaan $e$-learning yang dapat meningkatkan pelatihan dalam masa pandemi COVID-19 atau saat ini dikenal dengan era normal baru.

\section{DAFTAR PUSTAKA}

Damanik, R. D. N. (2020). Tata Kelola Pelaksanaan E-Learning Dalam Peningkatan Kinerja Penyelenggaraan Pelatihan Dalam Masa Covid-19. Jurnal AgriWidya, $1(3)$, 123-139. http://repository.pertanian.go.id/bitstream/handle/123456789/10229/Tata kelola pelaksanaan e-learning dalam meningkatkan kinerja penyelenggaraan pelatihan dalam masa covid-19.pdf?sequence $=1$ \&isAllowed $=\mathrm{y}$

Driscoll, D. (2018). The New RN and Emergency Patient Care Scenarios: How Simulation Can Help. OALib, 5(1), 1-22. https://doi.org/10.4236/oalib.1103904

Inggriyani, F., Fazriyah, N., \& Purbasari, A. (2019). Penggunaan E-Learning Berbasis Moodle bagi KKG Sekolah Dasar di Kecamatan Lengkong Kota Bandung. Jurnal SOLMA, 8(2), 268. https://doi.org/10.29405/solma.v8i2.3695 
Komisi Akreditasi Rumah Sakit. (2018). Instrumen Survey Standar Nasional Akreditasi Rumah Sakit (SNARS) Edisi 1. https://rspmanguharjo.jatimprov.go.id/wpcontent/uploads/2020/09/Instrumen-Survei-SNARS-ed-1-Tahun-2018-1.pdf

Lehtonen, M. R., Roos, M., Kantanen, K., \& Suominen, T. (2018). International Nursing: Nurse Managers' Leadership and Management Competencies Assessed by Nursing Personnel in a Finnish Hospital. Nursing Administration Quarterly, 42(2), 164-174. https://doi.org/10.1097/NAQ.0000000000000279

Lisum, K., \& Sianturi, S. R. (2020). Nursing Students' Perception of Their Learning Style. Jurnal Keperawatan, 11(2), 135-142. https://doi.org/10.22219/jk.v11i2.12478

Masiyati, E., Handiyani, H., \& Nurdiana, N. (2020). Pendidikan Berkelanjutan Nonformal Bagi Kepala Ruangan di Rumah Sakit X di Jakarta. Holistik Jurnal Kesehatan, 14(3), 409-419. https://doi.org/10.33024/hjk.v14i3.3171

Mellita, D., \& Elpanso, E. (2020). Model Lewin Dalam Manajemen Perubahan Teori Klasik Menghadapi Disrupsi Dalam Lingkungan Bisnis. Journal Management, Business, and Accounting, 19(2), 142-152. http://journal.binadarma.ac.id/index.php/mbia/article/view/989

Muhammad, H., Murtinugraha, R. E., \& Musalamah, S. (2020). Pengembangan Media Pembelajaran E-Learning Berbasis Moodle pada Mata Kuliah Metodologi Penelitian. Jurnal PenSil, 9(1), 54-60. https://doi.org/10.21009/jpensil.v9i1.13453

Oyenuga, G., Law, M., Parbat, M., \& Tofade, T. (2020). Implementing an Online Longitudinal Leadership Development Program Using a Leadership-Specific Continuing Professional Development (CPD) Tool. Pharmacy, 8(2), 1-9. https://doi.org/10.3390/pharmacy8020079

Pertiwi, B., \& Hariyati, R. T. S. (2019). The Impacts of Career Ladder System for Nurses in Hospital. Enfermeria Clinica, 29, 106-110. https://doi.org/10.1016/j.enfcli.2019.04.016

Quinn, B. (2017). Role of Nursing Leadership in Providing Compassionate Care. Nursing Standard, 32(16-19), 53-63. https://doi.org/10.7748/ns.2017.e11035

Setianingrum, R., \& Rachmi, S. F. (2019). Orientasi Perawat Baru di Rumah Sakit dengan Sistem E-Learning. Journal of Telenursing (JOTING), 1(2), 416-425. https://doi.org/https://doi.org/10.31539/joting.v1i2.932

Sulistiyowati, M. A. E. T. (2020). Gambaran Karakteristik Pembimbing Klinik. Jurnal Manajemen Asuhan Keperawatan, 4(1), 1-5. https://doi.org/10.33655/mak.v4i1.75

Zhang, M., Zhou, M., Tang, F., Wang, Y., Nie, H., Zhang, L., \& You, G. (2020). Knowledge, Attitude, and Practice Regarding COVID-19 Among Healthcare Workers in Henan, China. Journal of Hospital Infection, 105(2), 183-187. https://doi.org/10.1016/j.jhin.2020.04.012 